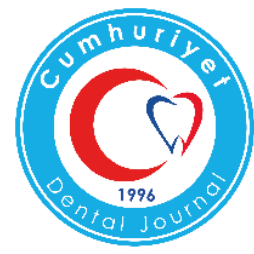

\title{
THE DENTAL PATHOLOGY ANALYSIS OF VAN-KARAGUNDUZ (MEDIEVAL AGE) ADULTS
}

Van-Karagündüz (Orta Çă̆) Erişkin Bireylerinin Dental Patoloji Analizi

\author{
Pınar GÖZLÜK KIRMIZIOĞLU
}

\author{
Makale Kodu/Article Code : 395212 \\ Makale Gönderilme Tarihi $\quad: 15.02 .2018$ \\ Kabul Tarihi \\ $: 27.02 .2018$
}

\section{ABSTRACT}

Objectives: The skeletal remains belonging to 188 individuals with jaws and teeth from the medieval cemetery region of the first structured level of the VanKaragündüz Höyük have been investigated in order to study the pathological lesions.

Materials and Methods: The material of this study is consisted of belonging to a total of 188 adult individuals, who composed from 81 women (43.09\%) and 107 men $(56,91 \%)$ (2734 permanent teeth and 283 jaws).

Results: In the permanent teeth of adults, tooth wear was $95.54 \%$, dental caries was $6.36 \%$, hypoplasia was $24.91 \%$, dental calculus was $25.90 \%$, abscess was $1.86 \%$, alveolar loss in periodontal diseases was $40.64 \%$ and (premortem) tooth loss is seen in proportion as $18,73 \%$.

Conclusions: The Karagündüz medieval society's nutrition regime, which is generally thought to have a lifestyle based on agriculture and animal husbandry, is generally consisted from well grinded, but somewhat fibrous and hard nutrients.

Keywords: Van-Karagündüz, Medieval, Teeth and Jaws Pathology
ÖZ

Amaç: Van-Karagündüz Höyüğü birinci yapı katında yer alan ve Ortaçağ Dönemi ile tarihlendirilen mezarlık alanından çıkarılan diş ve çenelere sahip 188 erişkin bireye ait iskelet kalıntıları; dişlerde ve çenelerde iz bırakan patolojik lezyonları incelemek amaciyla araştırılmıştır.

Gereç ve Yöntem: Çalışma materyalimizi 81 kadın $(\% 43,09)$ ve 107 erkek $(\% 56,91)$ olmak üzere toplam 188 erişkin bireye ait 2734 daimî diş ve 283 çene oluşturmaktadır.

Bulgular: Erişkinlerin daimî dişlerinde, diş aşınması $\% 95,54$, diş çürüğü \%6,36, hipoplazi \%24,91, diştaş1 $\% 25,90$, apse \%1,86, periodontal hastalıklar içinde değerlendirilen alveol kaybı \%40,64 ve ölüm öncesi (premortem) diş kaybı \%18,73 oranında görülmektedir.

Sonuç: Genel olarak tarım ve hayvancılığa dayalı bir yaşam biçimine sahip olduğu düşünülen Karagündüz Ortaçağ toplumunun beslenme rejimini, genellikle iyi ögütülmüş, fakat biraz lifli ve sert besinler oluşturmaktadır.

Anahtar kelimeler: Van-Karagündüz, Ortaçağ, Diş ve Çene Hastalıkları 


\section{GİRIŞ}

Karagündüz, Van ili merkezinin $35 \mathrm{~km}$. kuzeydoğusunda yer alan ve Van Merkez İlçe Erçek bucağına bağlı bir köydür. Araştırma kapsamında Karagündüz mevkiinde iki alanda kazı çalışması yapılmıştır. Bunlar Eski Karagündüz köyünde yer alan Karagündüz Höyügü ve bu höyüğün $1,5 \mathrm{~km}$. doğusundaki MÖ 1000 yıllarına tarihlendirilen Erken Demir Çağı Nekropol alanıdır. İlk olarak Karagündüz kazısı, 1992 yılında İstanbul Üniversitesi Edebiyat Fakültesi Van Bölgesi Tarih ve Arkeoloji Araştırmaları Merkezi ile Van Müze Müdürlüğü'nce ortaklaşa olarak bu nekropol alanında bir kurtarma kazısı olarak başlatılmış, daha sonra Erçek Gölü’nün giderek yükselmesi üzerine çalışmaların ağırlığı 1994 yılından itibaren höyüğe kaydırılmıştır. ${ }^{1-4}$

\section{GEREÇ ve YÖNTEM}

Çalışma materyalini 1994-1998 yılları arasında Van-Karagündüz Höyüğü'nde yapılan kazı çalışmaları sırasında, höyüğün birinci yapı katında yer alan ve Ortaçağ Döneme tarihlendirilen mezarlık alanından çıkarılan, toplam 188 erişkin bireye (81 kadın ve 107 erkek) ait 2734 daimi diş ve 283 çene oluşturmaktadır.

Bireylerde cinsiyet belirlenirken kemiklerin genel morfolojik yapılarına, özellikle kafatası ve pelvisteki cinsiyet kriterlerine bakılmış5 , yaşlandırmada ise, genç erişkinlerde epifizlerin kaynaşma yaşları, daimî dişlerin köklerinin kapanmas1 ${ }^{6,5,7}$, erişkin bireylerde sutural yaşlandırma ${ }^{8,5}$, symphysial yaşlandırma (Tood'un) ${ }^{9}$, dental aşınma ${ }^{7,10}$, claviculanın kesiti11, femur ve humerusun proksimal kesitindeki spongiosa dokusunun yap $1 s 1^{12}$ dikkate alınmıştır. Bunların yanı sıra birkaç kriterin ele alınmasıyla yapılan ve oldukça güvenilir sonuçlar veren kompleks yaşlandırma metodu ${ }^{13,5}$, gerekli iskelet materyallerinin bir arada bulunduğu durumda kullanılan bir başka yaşlandırma metodudur. Dişlerde ve çenelerdeki paleopatolojik bulguların saptanmasında ise Ortner ve
Putschar' $1 n^{14}$, Brothwell'in ${ }^{7}$, Bouville ve diğerlerinin ${ }^{15}$, Hillson'ın ${ }^{10}$ çalışmalarından yararlanılmıştır.

Karagündüz Ortaçağ toplumunun erişkinlerinde çene ve dişler üzerinde saptanan patolojik oluşumlarla ilgili bütün veriler SPSS programına yüklenerek aritmetik ortalamaları ve standart hataları belirlenmiştir. Ayrıca kadın ve erkek bireyler arasında, alt ve üst çenede bu oluşumların görülme farklılıklarının anlamlı olup olmadığının tespit edilmesi amacıyla, verilerimize $\mathrm{t}$ testi ve ki kare (X2) testi uygulanmıştır.

\section{BULGULAR}

Dişler paleoantropolojik araştırmalarda oldukça önemli materyallerdir. İskelet sisteminin en sert organı olan dişler, canlı öldükten sonra toprak altında uzun süre bozulmadan kalabilmekte ve kazılarda çoğunlukla sağlam olarak ve çok miktarda ele geçirilmektedir. Karagündüz Ortaçağ bireylerine ait dişler ve çeneler paleopatolojik açıdan incelenmiş ve bu bireylerde dental aşınma, diş çürügü, hipoplazi, diştaşı, apse, premortem (ölüm öncesi) diş kaybı ve alveol kaybı gibi lezyonlar belirlenebilmiştir (Tablo 1). ${ }^{16}$

Tablo 1. Karagündüz toplumunda erişkin bireylerde görülen diş ve çene patolojileri

\begin{tabular}{|l|c|c|c|c|c|c|c|c|c|}
\hline & Kadın & & & Erkek & & & Genel & & \\
\hline Dental Lezyonlar & B & G & $\%$ & B & G & $\%$ & B & G & $\%$ \\
\hline Çürük (diş) & 1185 & 86 & 7,26 & 1549 & 88 & 5,68 & 2734 & 174 & 6,36 \\
\hline Hipoplazi (diş) & 1185 & 386 & 32,57 & 1549 & 295 & 19,04 & 2734 & 681 & 24,91 \\
\hline Diştaşı (diş) & 1185 & 245 & 20,68 & 1549 & 463 & 29,89 & 2734 & 708 & 25,9 \\
\hline Apse (alveol) & 1577 & 27 & 1,71 & 1813 & 36 & 1,99 & 3390 & 63 & 1,86 \\
\hline Alveol Kaybı (çene) & 122 & 44 & 36,07 & 161 & 71 & 44,1 & 283 & 115 & 40,64 \\
\hline Premortem D.K. (alveol) & 1577 & 272 & 17,25 & 1813 & 363 & 20,02 & 3390 & 635 & 18,73 \\
\hline
\end{tabular}

\section{Diş Aşınması}

Diş aşınması, çiğneme esnasında dişlerin birbirlerine sürtünmeleri ve bu arada çiğnenen gıda içerisindeki sert cisimlerin yol açtığı tahribat sonucu diş minesinin giderek eksilmesidir. ${ }^{17}$ Karagündüz toplumu kadın ve erkek bireylerinin daimî dişlerinde \%95,54 oranında aşınma saptanmıştır (Resim 1). 


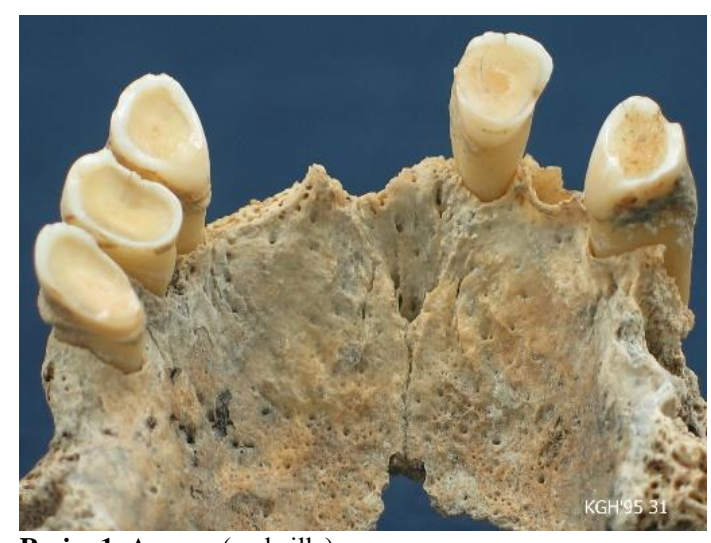

Resim 1. Aşınma (maksilla)

$\mathrm{Bu}$ oluşumdan en fazla etkilenen diş grubu 1. kesici dişler $(\% 46,15)$ olup, tüm daimî dişlerde lezyon çoğunlukla Brothwell'in7 derecelendirme sistemine göre az birikim derecesinde yoğunlaşmakta $(\% 69,21)$, bunu sirasiyla orta $(\% 24,66)$ ve ileri $(\% 6,13)$ birikim dereceleri izlemektedir. Karagündüz bireylerinin dişlerinde ileri derecede diştaş1 birikimi oldukça düşük bir değer ile karşımıza çıkmaktadır. $\mathrm{Bu}$ da bize diştaşı birikiminin alveol kaybı ve ölüm öncesi diş kaybı gibi patolojik lezyonların oluşumunda etkili olmakla birlikte, bu etkinin çok da fazla olmadığını düşündürmektedir. $\mathrm{Bu}$ toplumda, erkeklerde $(\% 29,89)$ kadınlara $(\% 20,68)$ nazaran daha fazla oranda diştaşı saptanmıştır. Diştaşı oluşumu özellikle lingual yüzeyde $(\% 44,41)$ yoğunlaşmaktadır. Bu oluşumdan ön dişler arka dişlere göre daha fazla etkilenmiştir.

\section{Apse}

Apse ileri derecedeki diş çürükleri ya da aşırı diş aşınmasının ardından pulpa boşluğunun iltihaplanmasinı ifade eden patolojik bir lezyondur. ${ }^{22}$ Karagündüz toplumunda apse oluşumu kadınlarda ve erkeklerde \%1,86 gibi oldukça düşük bir değer gösterir ve bu oluşumdan en fazla 1. büyük azı dişler $(\% 4,16)$ etkilenmiştir (Resim 5).

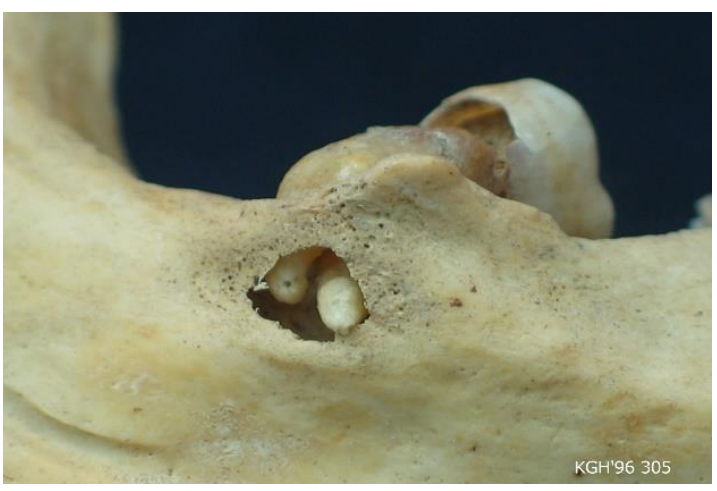

Resim 5. Apse ve çürük (mandibula)

Apse oluşumu arka dişlerde yanağa, ön dişlerde dudağa bakan tarafta daha yoğun olarak karşımıza çıkmaktadır. Dile bakan tarafta apse oluşumları daha azdır.

Populasyonda hem ileri derecede çürük hem de ileri derecede aşınmadan kaynaklı apse oluşumlarına rastlanırken, aşınma kaynaklı apseler biraz daha fazla görülmektedir. Bu toplumda apse oluşumundan erkekler $(\% 1,99)$ kadınlara $(\% 1,71)$ göre biraz daha fazla etkilenmiştir.

\section{Periodontal Hastalıklar (Alveol Kaybı)}

Alveol kaybı periodontal hastalıklar içinde değerlendirilmektedir. Periodontal hastalıklar mikroorganizmaların etkisiyle, dişetinin iltihaplanması sonucunda, dişeti ve alveol kemik çekilmesini ifade etmektedir., ${ }^{7,23-25}$ Periodontal hastalıklara yol açan etmenler arasında, ileri derecede çürük, aşınma, apse, yoğun diştaşı birikimi gibi oluşumlar sayılabilir. Karagündüz kadın ve erkek bireyleri alveol kaybı bakımından \%40,64 oranında bir değer vermektedir (Resim 6).

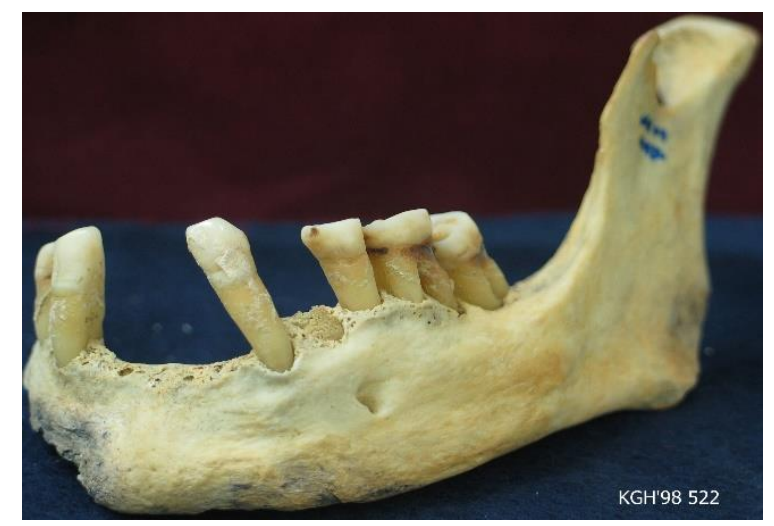

Resim 6. Alveol kaybı ve ölüm öncesi diş kaybı (mandibula) 
Kadın ve erkek bireylerde alt çene ve üst çeneler birlikte değerlendirildiğinde, populasyonda en fazla Brothwell' $\mathrm{in}^{7}$ derecelendirme sistemine göre orta düzeyde $(\% 46,09)$ bir alveol kaybına rastlanmaktadır. Bunu \%43,48 ile az ve \%10,43 ile ileri dereceler izlemektedir. Alveol kaybına erkek bireyler $(\% 44,10)$ kadınlara $(\% 36,07)$ göre daha fazla maruz kalmışlardır. Ancak incelenen materyalde alveol kaybına yol açacak patolojik lezyonlara çok belirgin olarak rastlanmamıştır.

\section{7.Ölüm Öncesi (Premortem) Diş Kaybı}

Premortem diş kaybı, bireyin ölümünden önce meydana gelen diş kaybıdır. Bu lezyona genellikle ileri derecedeki çürük ve aşınma, yoğun diştaşı birikimi ya da önemli periodontal rahatsızlıklar neden olmaktadır. ${ }^{10,14}$ Ölüm öncesi (premortem) diş kaybı incelenen erişkin bireylerde $\% 18,73$ oranında belirlenmiştir (Resim 7).

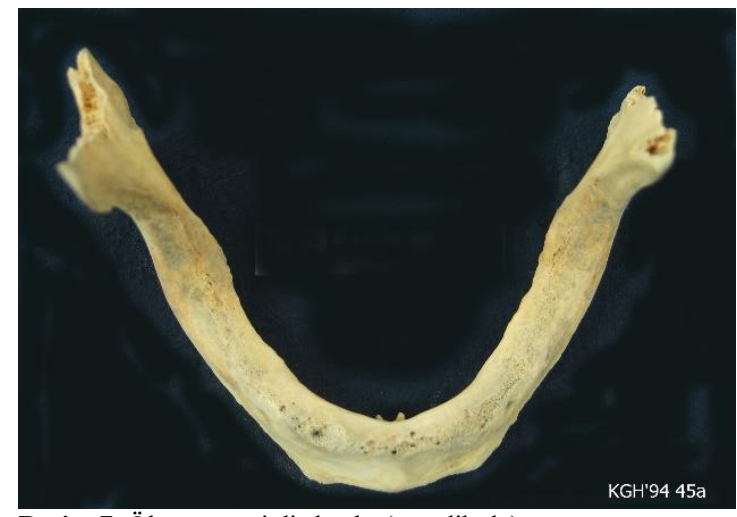

Resim 7. Ölüm öncesi diş kaybı (mandibula).

$\mathrm{Bu}$ oluşum en fazla 1. büyük azı dişlerini $(\% 35,21)$ etkilemiştir. Her iki cinsiyet grubunda da özellikle arka dişler ön dişlere oranla bu lezyona daha fazla maruz kalmışlardır.

Karagündüz toplumunda diştaş1, apse ve alveol kaybında olduğu gibi, ölüm öncesi diş kaybında da erkek bireyler $(\% 20,02)$ kadın bireylere $(\% 17,25)$ göre daha fazla etkilenmiştir. Aşınma oranları ise her iki cinsiyet grubunda birbirine yakın değerler verirken, hipoplazi ve çürük yüzdeleri kadınlarda erkeklere göre daha yüksek çıkmıştır. TARTIŞMA Geçmişte yaşamış insan topluluklarına ait dişlerin paleopatolojik açıdan incelenmesi, incelenen toplumların genel sağlık durumlarını, sosyo-ekonomik ve kültürel yapılarını, beslenme biçimlerini, yaşam şekillerini ortaya koyduğu gibi, bu verilerin günümüz toplumlarından elde edilen verilerle karşılaştırılması hastalıkların mevcut seyri hakkında bize oldukça önemli bilgiler vermektedir. Dişlerde ve çenelerde görülen patolojik lezyonların sıklığı, toplumların yaşam biçimi ile doğrudan ilişkilidir. Lukacs20 avc1-toplayıcı, karışık ve yoğun tarımın yapıldığı toplumlar ile diş ve çene hastalıkları arasında bir ilişki kurmuştur; avc1-toplayıcı toplumlarda diş çürüğü, hipoplazi, diştaşı, alveol kaybı düşük, diş aşınma şiddeti daha yüksek iken, karışık beslenme sisteminde bu lezyonlar orta derecededir. Yoğun tarımın yapıldığ1 toplumlarda ise avc1 toplayıc1 toplumların tersine diş çürüğü, hipoplazi, diştaşı, alveol kaybı yüksek, diş aşınma şiddeti de daha düşük değerlerdedir.

Karagündüz toplumu erişkin bireylerinin daimî dişlerinde \%95,54 oranında aşınma saptanmıştır. Aşınmalar yoğunlukla orta düzeydedir ve en fazla rastlanan aşınma derecesi de "4"tür. Elde edilen değer diğer eski Anadolu toplumlarından elde edilen değerlerle karşılaştırıldığında, Karagündüz erişkin bireyleri aşınma derecesi bakımından birçok topluma benzerlik göstermektedir.16

İncelenen toplumda erişkin bireylerden elde edilen diş ve çene patoloji sonuçları, diğer eski Anadolu toplumlarından elde edilen sonuçlarla karşılaştırıldığında şöyle bir tablo ortaya çıkmaktadır (Tablo 2);

Tablo 2. Karagündüz Höyüğü Ortaçağ toplumunda diş ve çene patolojilerinin diğer eski Anadolu toplumlarıyla karșılaștırılması

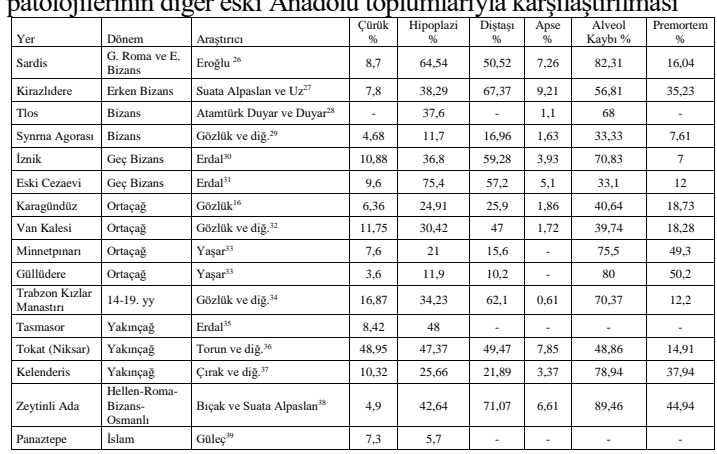


Karagündüz Ortaçă̆ toplumu farklı dönemlerde ve farklı yerleşim yerlerinde yaşamış olan diğer eski Anadolu toplumlariyla karşılaştırıldığında, dişlerde ve çenelerde görülen bütün lezyonlar açısından en fazla, kendisiyle aynı coğrafik bölgede yer alan ve çağdaşı Van Kalesi Ortaçağ $\breve{~}^{32}$ toplumuna yaklaşmaktadır.

İlerlemiş derecede çürük, aşınma, apse, yoğun diştaşı birikimi periodontal hastalıklara ve alveolar yıkıma neden olabilmekte ve bu nedenlerden dolayı da birey hayatta iken dişlerini kaybedebilmektedir. Karagündüz toplumunda çürük $(\% 6,36)$ ve apse $(\% 1,86)$ yüzdesi diğer eski Anadolu toplumlarına göre düşük değerlerle karşımıza çıkmaktadır. Diştaşı birikimi ise yoğunlukla az derecededir. Dolayısıyla bu oluşumun alveol kaybında etkili olduğu, fakat bu etkinin az olduğu düşünülmektedir. Alveol kaybı çoğunlukla az ve orta derecelerde yoğunlaşmakta, diğer eski Anadolu toplumlarına göre yüksek bir değer göstermemektedir. Bununla birlikte populasyonda bu oluşumu meydana getiren çok belirgin patolojik lezyonlar sınırlı sayıdadır. Birkaç diş örneğinde de ileri derecede aşınma meydana getiren abrazyona rastlanması dikkat çekicidir. Özellikle ileri derecelerde aşınmalar, ilerlemiş çürüklere nazaran apse oluşumunda biraz daha fazla etkili olmuştur. Toplumda görülen yüksek premortem diş kaybı değeri, ilerlemiş çürük ya da ileri derecelerdeki aşınmalar dışında yaşla ilişkilendirilmektedir. İncelenen toplumda rastlanan bir diğer lezyon olan hipoplazide, eski Anadolu toplumlarının bir kısmına yakın bir değer vermektedir. Özellikle az derecede gelişim gösteren bu oluşum, dişlerde genelde devamlı şekildedir. Travmadan kaynaklı herhangi bir durum söz konusu değildir.

Karagündüz alüvyonlu düzlükleri hem coğrafik hem de beslenme koşulları açısından yıllar boyunca Van ili çevresinde insanoğlunun yerleşmesine en uygun köşelerden birini oluşturan olanaklara sahiptir. Çevre koşullarına baktı̆̆ımızda, o dönemle günümüz arasında önemli bir fark görülmemektedir. Büyük bir olasilıkla Doğu Anadolu Bölgesinde o dönemdeki mevcut bitki örtüsü günümüz bitki örtüsü ile benzerdir. Ancak, yapılan kazılar, daha çok höyügün tepesindeki kilise etrafına yayılmış olan mezarlıkta gerçekleştirildiği, Ortaçağ köyü fazla incelenemediği için, o dönem insanlarının günlük yaşamları konusunda çok da sağlıklı verilere ulaşılamamıştır. Ancak Karagündüz Höyüğü'nün 2. Ortaçağ katında çok miktarda tahıl çukurlarına ve tandırlara rastlanmış olması, Ortaçağ insanlarının bol miktarda buğday ektiklerini ve hayvanları için yonca, korunga yetiştirdiklerini göstermektedir. Ayrıca bu insanların kerpiç evlerde oturdukları, ekmeklerini köy meydanındaki büyük tandır ve firınlarda pişirdikleri, oldukça soğuk bir iklime sahip bu yörede yakıt olarak tezeğin kullanıldığ arkeolojik buluntulardan anlaşılmaktadır (Prof. Dr. Veli Sevin ile sözlü görüşme). Bütün bu bilgiler 1şığında Van-Karagündüz populasyonunda görülen beslenme rejiminin, genellikle Doğu Anadolu'da yaşayan diğer topluluklarda karşımıza çıkan beslenme sistemiyle büyük bir uyum gösterdiği söylenebilir. ${ }^{16}$

Geçmişten günümüze Doğu Anadolu'da yaşayan toplumların büyük bir kısmı tarım ve hayvancılıkla uğraşmışlar ve teknolojik gelişmelere de paralel olarak, besin hazırlama tekniklerinde farklılaşma göstermişlerdir. Özellikle Anadolu'da eskiden yaşamış birçok toplumda görüldüğü gibi, tahılların bazalttaş blok üzerinde ögütülmeleri sırasında kopan ve tahıla karışan taş parçacıkları, diş minesinde abrazyona yol açmaktadır. Bu Anadolu'da çok sık karşılaşılan bir durumdur. Karagündüz toplumunda da az da olsa abrazyona rastlanması besinlerin hazırlanışı esnasında çok da özenli davranılmadığını, besin maddelerinin içine aşındırıcıların karıştı̆̆ını göstermektedir. Karagündüz Ortaçağ toplumunun dişlerinde ve çenelerinde görülen patolojilere göre genel beslenme rejimini, genelde iyi öğütülmüş, fakat biraz lifli ve sert besinlerin oluşturduğu, bununla birlikte besinlerin hazırlanışı sırasında, içlerine az da olsa aşındırıcı sert 
maddelerin karıştığ beslenme sistemlerinde karbonhidratl ve şekerli besinlerin mevcut olduğu, fakat bunların çok yoğun bir şekilde tüketilmediği ve aynı zamanda beslenme sistemlerinde hayvansal proteinlere de yer verdikleri söylenebilir.

Van-Karagündüz Höyüğü Ortaçağ populasyonuna diş ve çene hastalıkları yönünden, Doğu Anadolu Bölgesinde eskiden yaşamış diğer toplumların birçoğu benzerlik göstermektedir. $\mathrm{Bu}$ da aynı bölgede farklı dönemlerde yaşamış toplumların hemen hemen benzer bir beslenme rejimine sahip olduğunu düşündürmektedir.

\section{TEŞEKKÜR}

$\mathrm{Bu}$ iskeletleri çalışmamız için izin veren VanKaragündüz kazı başkanı Prof. Dr. Veli Sevin'e, bu çalışmayı hazırlamam sırasında desteklerini ve yardımlarını esirgemeyen sevgili doktora danışman hocam Prof. Dr. Ayla Sevim Erol'a, tüm çalışma boyunca yanımda olan ve yardımlarını esirgemeyen sevgili arkadaşım Öğr. Gör. Ayhan Yiğit'e sonsuz teşekkür ederim.

\section{KAYNAKÇA}

1. Sevin V., Kavaklı E. Van - Karagündüz Erken Demir Çağ1 Nekropolü Kurtarma Kazıları 1992-1993. 16. Kazı Sonuçları Toplantıs1 1995a; 1: 331-350.

2. Sevin V., Kavaklı E. Bir Erken Demir Çağ Nekropolü: Karagündüz. İstanbul: Arkeoloji ve Sanat Yayınları, 1995b.

3. Sevin V., Kavaklı E., Özfirat A. Karagündüz Höyüğü ve Nekropolü 1995-1996 Yı1ı Kurtarma Kazıları. 19. Kazı Sonuçları Toplantis1 1998: 1: 571-589.

4. Sevin V., Özfırat A. Van-Karagündüz Kazıları. In: Belli O. (eds). Türkiye Arkeolojisi ve İstanbul Üniversitesi (1932-1999). İstanbul: İstanbul Üniversitesi, 2000: 168-174.

5. Workshop of European Antropologists (WEA). Recommendations for Age and Sex
Diagnoses of Skeletons. Journal of Human Evolution 1980; 9 (7): 517-549.

6. Ubelaker, DH. Human Skeletal Remains: Excavation, Analysis, Interpretation. Chicago: Smithsonian Institution, Aldire Publishering Company, 1978.

7. Brothwell D.R. (1981). Digging up Bones, 3. Press, Oxford University Press, London.

8. Olivier G. Practical Anthropology. Springfield, Illionis: Charles C. Thomas Publisher, 1969.

9. White DT. Human Osteology. U.S.A: Academic Press, 1991.

10.Hillson S. Teeth, New York: Cambridge University Press, 1990.

11.Kaur H., Jit I. Age Estimation from Cortical Index of the Human Clavicle in Northwest Indians. American Journal of Physical Anthropology 1990; 83: 297-305.

12. Szilvassy J., Kritscher H. Estimation of Chronological Age in Man Based on the Spongy Structure of Long Bones. Anthrop. Anz. 1990; 48 (3): 289-298.

13.Acsadi GY., Nemeskeri J. History of Human Life Span and Mortality. Budapeşte: Akademia Kiado,1970.

14. Ortner DJ., Putschar WGJ. Identification of Pathological Conditions in Human Skeletal Remains. Washington: Smithsonian Institution Press, 1985.

15.Bouville C., Constanse-Westerman TS., Newell R.R. Les Restes Humains Mesolithiques de L'Abri Cornille, Istres (Bouches-du Rhane). Bull. et. Mem. de la Soc. d' Anthrop. de Paris 1983; 13: 89-110.

16.Gözlük $\quad P$. $\quad$ Van-Karagündüz Populasyonunun Dişlerinin ve Çenelerinin Paleopatolojik Açıdan İncelenmesi. Basılmamış Doktora Tezi, Ankara: Ankara Üniversitesi Sosyal Bilimler Enstitüsü, 2004.

17.Özbek M. Dünden Bugüne İnsan, Ankara: İmge Kitabevi, 2000.

18.Freeth C. Dental Health in British Antiquity. In: Cox M, Mays S (eds). Human Osteology in Archaeology and Forensic 
Science. London: Greenwich Medical Media Ltd., 2000: 227-237.

19.Goodman AH., Armelagos GJ., Rose JC. Enamel Hypoplasias as Indicators of Stress in Three Prehistoric Populations from Illionis. Human Biology 1980; 52: 515-528.

20.Lukacs JR. Dental Paleopathology: Methods for Reconstructing Dietary Patterns. In: İşcan MY, Kennedy, KAR (eds). Reconstruction of Life from the Skeleton. New York: Alan R. Liss Inc., 1989: 261-286.

21.Langsjoen O. Diseases of the Dentition. In: Aufderheide AC, Rodriguez-Martin, C (eds). The Cambridge Encyclopedia of Human Paleopathology. New York: Cambridge University Press, 1998: 393-412.

22. Buikstra JE., Ubelaker DH. Standards for Data Collection from Human Skeletal Remains. Research Series, No. 44. Fayetteville: Arkansas Archaeological Survey, 1994.

23. Clarke NG., Carey SE., Srikandi W., Hirsch RS., Leppard PI. Periodontal Disease in Ancient Populations. American Journal of Physical Anthropology 1986; 71: 173-183.

24.Roberts C., Manchester K. The Archaeology of Disease. 2. Basım, New York: Cornell University Press, 1995.

25.Özbek M. Çayönü Tarım Toplumunda Diş Sağlığı. Türk Arkeoloji Dergisi 1997; 31: 181216.

26.Eroğlu, S. Sardis Roma-Bizans Toplumlarında Diş Hastalıkları ve Ağız Sağllğı. Basılmamış Yüksek Lisans Tezi, Ankara: Ankara Üniversitesi Sosyal Bilimler Enstitüsü, 1998.

27. Suata Alpaslan F., Uz B. Kirazlıdere İskelet Topluluğunun Çene Ve Diş Patolojisi Açısından İncelenmesi. Cumhuriyet üniversitesi Edebiyat Fakültesi Sosyal Bilimleri Dergisi, 2017; 41(2): 1-19

28. Atamtürk Duyar D., Duyar, İ. Tlos İskeletlerinin Antropolojik Analizi. Arkeometri Sonuçları Toplantısı 2011; 27: 331-346.

29.Gözlük P., Durgunlu Ö., Özdemir S., Taşlıalan M., Sevim A. Symrna Agorası
İskeletlerinin Paleoantropolojik Analizi. Arkeometri Sonuçları Toplantısı 2005; 21: 125-140.

30.Erdal Y.S. İznik Geç Bizans Dönemi İnsanlarının Çene ve Dişlerinin Antropolojik Açıdan İncelenmesi. Basılmamış Doktora Tezi, Ankara: Hacettepe Üniversitesi Sosyal Bilimler Enstitüsü, 1996.

31.Erdal Y.S. Büyük Saray-Eski Cezaevi-Eski Cezaevi Çevresi Kazılarında Gün Işığına Çıkarılan İnsan Kalıntılarının Antropolojik Analizi. Arkeometri Sonuçları Toplantısı 2003; 18: 15-30.

32.Gözlük P., Yiğit A., Erkman AC. Van Kalesi/Eski Van Şehri İnsanlarındaki Sağlık Sorunları. Arkeometri Sonuçları Toplantısı 2004; 19: 51-62.

33. Yaşar ZF. Adli Dental Antropoloji: (Dental Antropoloji Açısından Minnetpınarı ve Güllüdere Toplumlarının Dişlerinin Karşılaştırmalı Analizi. Basılmamış Doktora Tezi, Ankara: Ankara Üniversitesi Sosyal Bilimler Enstitüsü, 2007.

34.Gözlük Kırmızığlu P., Yaşar ZF., Yiğit A., Suata Alpaslan F., Sevim Erol A., Kesikçiler B. Trabzon Kızlar Manastırı İskeletlerinde Ağız ve Diş Sağlığı. Arkeometri Sonuçları Toplantıs1 2010; 25: 127-150.

35.Erdal YS. Tasmasor Yakınçağ Nekropolü ve İskeletlerinin Antropolojik Açıdan Değerlendirilmesi. In: Şenyurt SY (eds). Tasmasor. Ankara: Bilgin Kültür Sanat Yayınları, 2011: 259-326.

36.Torun N., Gözlük Kırmızıoğlu P. Tokat (Niksar) İskeletlerinde Diş ve Çene Patolojileri. CÜ Sosyal Bilimler Dergisi 2015; 39 (2): 47-70.

37.Çırak A., Çırak MT., Erkman AC. Kelenderis Halkının Diş ve Çene Paleopatolojileri. OLBA 2013; 21:1-25.

38.Bıçak S. ve Suata Alpaslan F. Zeytinli Ada İskelet Topluluğunun Diş ve Çene Patolojisi Açısından İncelenmesi. Cumhuriyet üniversitesi Fen Fakültesi Fen Bilimleri Dergisi, 2015; 36(5): 32-46. 
39.Güleç E. Panaztepe İskeletlerinin

Paleoantropolojik ve Paleopatolojik İncelemesi.

Türk Arkeoloji Dergisi 1989; 28: 73-95.

\section{Yazıssma Adresi}

Pınar GÖZLÜK KIRMIZIOĞLU

Cumhuriyet Üniversitesi

Edebiyat Fakültesi

Antropoloji Bölümü

Sivas / Türkiye

Tel. : :03462191010/4287

Cep Tel.: 05337753481

E-posta : pinar.gozluk@gmail.com 